\title{
Memantine reduces consumption of highly palatable food in a rat model of binge eating
}

\author{
Piotr Popik - Tomasz Kos • Yulei Zhang • \\ Adam Bisaga
}

Received: 24 December 2009/Accepted: 11 June 2010/Published online: 23 June 2010

(C) The Author(s) 2010. This article is published with open access at Springerlink.com

\begin{abstract}
Excessive consumption of highly palatable food has been linked to the development of eating disorders and obesity, and can be modeled in non-food-deprived rats by offering them a limited (2-h daily) access to an optional dietary fat. Since the glutamatergic system has recently emerged as a viable target for binge-eating medication development, we compared the effects of subchronic treatment with glutamatergic receptor antagonists to the effects of a reference appetite-suppressing agent sibutramine on highly palatable food (lard) and normal chow intake. In three separate experiments, the consumption of a standard laboratory chow and lard were measured during 12 days of medication treatment and for 6 days afterwards. Generalized estimating equations analysis demonstrated that sibutramine $(7.5 \mathrm{mg} / \mathrm{kg}$, PO) significantly decreased lard consumption, with a concurrent increase in chow consumption. Sibutramine effects disappeared after treatment discontinuation. The NMDA receptor antagonist memantine $(5 \mathrm{mg} / \mathrm{kg}$, IP) significantly decreased lard consumption and increased chow consumption, comparable to effects of sibutramine; however, memantine's effects persisted after treatment discontinuation. The effects of the mGluR5 antagonist MTEP $(7.5 \mathrm{mg} / \mathrm{kg}$, IP) on food consumption were in the same direction as seen with memantine, but the observed differences were not significant. In an additional control experiment, sibutramine and memantine reduced unlimited $(24 \mathrm{~h})$ chow intake during
\end{abstract}

P. Popik $(\bowtie) \cdot$ T. Kos

Behavioral Neuroscience, Institute of Pharmacology Polish Academy of Sciences, 12 Smetna Street, 31-343 Krakow, Poland e-mail: nfpopik@cyf-kr.edu.pl

Y. Zhang · A. Bisaga

Department of Psychiatry, Columbia University

College of Physicians and Surgeons, New York, USA the treatment phase. Present results provide evidence that glutamatergic neurotransmission might be involved in the regulation of excessive consumption of highly palatable foods, and suggest that NMDA receptor may be an attractive target for developing obesity and disordered eating pharmacotherapies.

Keywords Binge eating - Compulsive behavior . Generalized estimating equations · Memantine · mGluR5 antagonist $\cdot$ Sibutramine

\section{Introduction}

Excessive, non-homeostatic consumption of highly palatable food has been linked to eating disorders and obesity (Berthoud 2004; Blundell and Finlayson 2004; Boggiano et al. 2009; Hagan et al. 2003; Vartanian et al. 2007; Walsh and Devlin 1998). Exposure to highly palatable food disrupts natural mechanisms of appetite regulation and results in abnormal patterns of consumption such as binge-eating and compulsive overeating (Devlin et al. 2000; ErlansonAlbertsson 2005; Fairburn et al. 2000; Tanofsky-Kraff et al. 2006).

Development of animal models of binge-type consumption of highly palatable food can hasten study of underlying mechanisms and discovery of pharmacotherapies (Avena et al. 2009; Bisaga et al. 2008; Cifani et al. 2009; Corwin and Buda-Levin 2004; Foltin et al. 2008; Wojnicki et al. 2008a). In one such model, non-fooddeprived laboratory rats with unlimited access to chow are offered a limited access to an optional source of dietary fat. After several weeks of limited access to fat and a continuous access to chow, the rats develop eating pattern characterized by consumption of large amounts of the fat 
during brief access periods ( $2 \mathrm{~h}$ per day) and this effect is enhanced when the fat is offered only three times per week (Buda-Levin et al. 2005; Corwin and Buda-Levin 2004; Corwin et al. 1998; Wojnicki et al. 2008a, b; Wong et al. 2009). It has been proposed that this behavioral paradigm can be used as a model of binge-eating, as it mimics features of clinical syndrome such as rapid consumption of highly palatable food (Devlin et al. 2003; Weltzin et al. 1991). However, its predictive validity to detect effects of anti-binge medications is less known (Buda-Levin et al. 2005). The first goal of the present study was thus to assess the utility of the limited access model as a screening tool in binge-eating pharmacotherapy development using sibutramine, a prototypic weight loss medication that has been found to reduce binge-eating in patients with binge-eating disorder (Wilfley et al. 2008). In order to assess the selectivity of medication effect on the consumption of lard in the situation of choice, we have conducted a separate experiment evaluating the effect of sibutramine on the consumption of chow, available $24 \mathrm{~h}$ per day.

The glutamatergic neurotransmitter system is a viable target for binge-eating disorder medication development in view of its role in the reinforced and consummatory behaviors produced by drugs of abuse and highly palatable food (Bisaga and Popik 2000; Bradbury et al. 2005; Gass and Olive 2008; Herman et al. 2003; Popik et al. 2003). We have previously shown in baboons, that single doses of memantine and MTEP produce decrease in the consumption of highly palatable food (candy) comparable to effects of dexfenfluramine, another prototypic binge-eating reducing medication (Bisaga et al. 2008; Foltin et al. 2008). The second goal of the present study was therefore to evaluate the effects of the NMDA receptor antagonist memantine and the mGluR5 antagonist MTEP and to compare those effects to the effects of sibutramine in the limited-access animal model of binge-eating of highly palatable food (lard) and on the consumption of chow available at all times. We were interested in evaluating effects of repeated drug treatment as well as drug carryover effects, because longer-term dosing is more relevant to the clinical medication development. We hypothesized, that memantine and MTEP would have an effect comparable to the effect of sibutramine.

\section{Materials and methods}

\section{Subjects}

All experimental procedures were conducted in accordance with the NIH Guide for the care and use of laboratory animals and were approved by the Ethics Committee for animal experiments, Institute of Pharmacology. Male
Sprague-Dawley rats (Prokocim, Kraków, Poland) weighing $\sim 300 \mathrm{~g}$ were housed individually at $21 \pm 2^{\circ} \mathrm{C}$ (A/C controlled) on the 12-h light/dark cycle (lights on 06:00).

\section{Procedure}

The present work consisted of two sets of experiments. In experiments $1-3$, we separately tested the effects of medications in the limited access to the lard model and in experiment 4 , we tested the effects of medications and vehicle on the unlimited chow consumption.

\section{Experiments 1-3}

A modified limited access procedure (Corwin et al. 1998) was used to induce binge-type consumption of lard. Throughout the 6 weeks of the study, rats had an unlimited access to the standard laboratory chow (Labofeed $\mathrm{H}$, Kcynia, Poland, containing $3.12 \mathrm{kcal} / 1 \mathrm{~g}: 22 \%$ protein, $4 \%$ fat, $11.5 \%$ fibers and ashes) and tap water. In addition, a feeder with lard (JAGR, Warlubie, Poland, $9.0 \mathrm{kcal} / 1 \mathrm{~g}$ : $100 \%$ fat) was introduced daily for $2 \mathrm{~h}$, starting $2 \mathrm{~h}$ prior to lights out (Lard Session). After 3 weeks of individual housing, a consumption of lard and chow had stabilized (data not shown) and the drug administration was initiated. In view of the fact that sibutramine, memantine and MTEP had a different route of administration and different vehicles, three separate experiments were conducted consecutively. In each, two groups of rats were matched by the amount of lard consumed during the pre-treatment phase and assigned to receive the study drug or its vehicle. A disadvantage of such experimental design was that the experiments were carried out at different seasons of the year, using animals that differed in the baseline body weight and amount of food consumed. The drugs were given once daily for 12 consecutive days (Treatment Phase), immediately prior to the Lard Session, i.e., at 1600 hours. Following Treatment Phase, animals were given vehicle daily for 6 days while other study procedures were identical and food consumption was monitored, to investigate possible carryover effects (Post-Treatment Phase). Nine animals were assigned to each sibutramine and its vehicle groups (Exp. 1), 10 animals assigned to each memantine and its vehicle groups (Exp. 2), and 8 animals assigned to each MTEP and its vehicle groups (Exp. 3).

\section{Experiment 4}

In a separate control experiment, a group of different rats was acclimated to cages with an unlimited access to the standard laboratory chow and tap water (continuous access to chow procedure). After the initial phase of individual housing lasting for 2 weeks, the consumption of chow 
stabilized (data not shown) and rats were separated into four groups. Each group was assigned to receive one of the three study drugs or the vehicle. The drugs were given at 1600 hours once daily for 7 consecutive days (Treatment Phase), after the assessment of previous day's chow consumption. Following Treatment Phase, animals were given vehicle, but other study procedures were identical and food consumption was monitored daily for 5 days of PostTreatment Phase. Twelve animals were assigned into each of the study drugs and 13 animals were assigned into the pooled vehicle group (5 received saline IP, 4 received Tween IP, and 4 received Tween PO).

\section{Drugs}

MTEP HCl (3-[(2-methyl-1,3-thiazol-4-yl)ethynyl]pyridine, MERZ Pharmaceuticals) and sibutramine $\mathrm{HCl}$ (Abbott; purchased as a commercial formulation) were suspended right before administration in $1 \%$ Tween $80 /$ distilled water solution with $\mathrm{pH}$ adjusted 6-6.5 with $\mathrm{NaOH}$. Memantine $\mathrm{HCl}$ (MERZ Pharmaceuticals) was dissolved in sterile physiological saline. MTEP $(7.5 \mathrm{mg} / \mathrm{kg})$ and memantine $(5 \mathrm{mg} / \mathrm{kg})$ and their respective vehicles were given IP, while sibutramine $(7.5 \mathrm{mg} / \mathrm{kg})$ and its vehicle were administered PO. The doses of sibutramine, memantine and MTEP were chosen based on earlier observations showing inhibitory effects of these compounds on either food intake or reinforcing effects of abused drugs (Bradbury et al. 2005; Jackson et al. 1997; Popik et al. 2003, 2006).

\section{Statistical analyses}

In the limited access experiments (Experiments 1-3; with sibutramine, memantine, and MTEP, respectively), the amounts of lab chow and the lard consumed during the 2-h Lard Session were measured daily and recalculated as energy (Kcal) per body weight in grams. Food consumption was measured for 12 consecutive days during drug treatment (Treatment Phase) and for 6 consecutive days afterwards (Post-Treatment Phase). In Experiments 1-3, we evaluated the effect of Drug (active or vehicle), Food type (lard or chow), phase (Treatment or Post-Treatment), and Time (day as a continuous variable) on food consumption.

In the continuous access experiment (Experiment 4), the amount of lab chow consumed during $24 \mathrm{~h}$ was measured daily and recalculated as energy (Kcal) per body weight in grams. Food consumption was measured at pre-treatment baseline, for 7 consecutive days during drug treatment (Treatment Phase) and for 5 consecutive days afterwards (Post-Treatment Phase). In this experiment, we evaluated the effects of drug (sibutramine, memantine, or MTEP), phase (Treatment or Post Treatment) and time (days as a continuous variable).
The choice of this statistical method deserves a brief note. Traditional test statistics such as the $\chi^{2}$ or $t$ test could not be used to test for food and drug-related differences in Experiments 1-3 due to the lack of independence across measurements (i.e., consumption of one food being correlated with consumption of another food) and our interest in consumption changes over time. To address this issue, we used generalized estimating equations (GEE) statistical approach involving estimation of marginal models to fit consumption as a function of drug, food type, phase, and time as well as all their interactions. A backward elimination procedure starting with the four-way interaction was used to select the best-fit, final model. The GEE approach for repeated measurements was used to estimate and test the model. This procedure is best suited to analyze correlated data obtained in longitudinal studies, which allows to test the effect of intervention at various time-points during treatment and at follow-up (Lee et al. 2007; Zeger and Liang 1986). The GEE methodology requires no parametric distribution assumption, provides robust inference with respect to misspecification of the within subject correlation and allows for the analysis of continuous, categorical and count data. PROC GENMOD in SAS 9.1 was used to carry out analyses. A one-way ANOVA with Tukey's HSD post hoc test was used to conduct additional analyses in experiment 4.

Changes in body weight of the rats used in experiments 1-4 were assessed independently for each experiment with the use of two-way repeated measures ANOVAs with the week as the repeated factor and treatment as the betweensubjects factor.

\section{Results}

\section{Experiment 1}

For sibutramine dataset, a parsimonious model for lard and chow consumption was used (Table 1; Fig. 1a). Throughout the observation period, animals consumed more lard than chow $\left(\chi^{2}=5.87, p=0.015\right)$.

Sibutramine decreased overall food consumption ( $p=0.028)$; however, this effect was different for lard and chow (significant Drug $\times$ Food interaction $p=0.049$ ). While sibutramine decreased the consumption of lard, it increased the consumption of chow. The effect of sibutramine on lard and chow consumption disappeared during the Post-Treatment Phase.

\section{Experiment 2}

For memantine dataset, the separate models for lard and chow consumption were fitted since the parsimonious 
Table 1 Sibutramine experiment GEE score statistics with food consumption as outcome variable

\begin{tabular}{lrrr}
\hline Source & \multicolumn{1}{l}{ BSE } & $\chi_{(1)}^{2}$ & $p$ Value \\
\hline Intercept & $317.4(90.0)$ & & \\
Food $^{\mathrm{a}}$ & $-\mathbf{2 9 1 . 1}(\mathbf{9 6 . 7})$ & $\mathbf{5 . 8 7}$ & $\mathbf{0 . 0 1 5 4}$ \\
Drug $^{\mathrm{b}}$ & $-\mathbf{2 9 7 . 5 ( 1 0 3 . 4 )}$ & $\mathbf{4 . 8 4}$ & $\mathbf{0 . 0 2 7 8}$ \\
Drug $\times$ food & $\mathbf{3 1 9 . 6 ( 1 1 7 . 4 )}$ & $\mathbf{3 . 8 7}$ & $\mathbf{0 . 0 4 9 1}$ \\
Time & $-6.17(2.23)$ & 2.20 & 0.1382 \\
Time $\times$ food & $5.68(2.42)$ & 0.46 & 0.4966 \\
Time $\times$ drug & $\mathbf{7 . 4 8}(\mathbf{2 . 6 1})$ & $\mathbf{4 . 1 7}$ & $\mathbf{0 . 0 4 1 2}$ \\
Time $\times$ drug $\times$ food & $-8.06(3.00)$ & 2.85 & 0.0916 \\
Phase & $\mathrm{-244.9}(\mathbf{8 6 . 6})$ & $\mathbf{4 . 8 1}$ & $\mathbf{0 . 0 2 8 2}$ \\
Phase $\times$ food & $223.6(89.7)$ & 1.03 & 0.3102 \\
Drug $\times$ phase & $\mathbf{2 9 6 . 7 ( 1 0 1 . 9 )}$ & $\mathbf{4 . 6 0}$ & $\mathbf{0 . 0 3 1 9}$ \\
Drug $\times$ phase $\times$ food & $-\mathbf{3 3 1 . 3}(\mathbf{1 1 0 . 8})$ & $\mathbf{5 . 9 7}$ & $\mathbf{0 . 0 1 4 6}$ \\
Time $\times$ phase & $\mathbf{7 . 2 1}(\mathbf{2 . 4 8})$ & $\mathbf{5 . 0 4}$ & $\mathbf{0 . 0 2 4 8}$ \\
Time $\times$ phase $\times$ food & $-6.74(2.50)$ & 1.54 & 0.2147 \\
Time $\times$ drug $\times$ phase & $\mathbf{- 8 . 2 5 ( 2 . 9 7 )}$ & $\mathbf{3 . 9 9}$ & $\mathbf{0 . 0 4 5 9}$ \\
Time $\times$ drug $\times$ phase $\times$ food & $\mathbf{9 . 4 0}(\mathbf{3 . 1 4})$ & $\mathbf{5 . 9 7}$ & $\mathbf{0 . 0 1 4 6}$ \\
\hline
\end{tabular}

Effects in table are food type (lard or chow), drug (sibutramine or vehicle), phase (Treatment or Post-Treatment), and time-receiving treatment is in units of days (22-33) for consumption outcome (kcal/ $\mathrm{kg}$ b.w.). Bold $p$ values denote significant effects

${ }^{a}$ Lard was used as the reference

b Vehicle was used as the reference

${ }^{c}$ Post-treatment phase was used as the reference

model could not provide reasonable fit for both food types simultaneously (Table 2; Fig. 1b).

For Lard, memantine decreased overall consumption $(p=0.028)$. There was a marginal effect of Phase $(p=0.052)$ and a significant Time $\mathrm{x}$ Phase interaction $(p=0.03)$, indicating that lard consumption increased over time in the Treatment Phase while it decreased in PostTreatment Phase.

For Chow, memantine increased overall consumption $(p=0.003)$, with the drug effect appeared significantly greater for Treatment than for the Post-Treatment Phase (significant Drug $\times$ Phase interaction $p=0.05$ ).

\section{Experiment 3}

For MTEP dataset, separate models for lard and chow consumption were used for the same reason as in memantine dataset (Table 3; Fig. 1c).

Animals treated with MTEP consumed less lard, but this effect was not significant $(p=0.196)$. There was no significant difference between two Treatment groups and different Treatment Phases and there was no significant Time trend.

For the chow, MTEP appeared to increase consumption during Treatment Phase, however, the drug effect disappeared after treatment was stopped (significant Drug $\times$ Phase interaction $p=0.004)$ rendering overall drug effect statistically not-significant $(p=0.075)$.

\section{Experiment 4}

In the GEE model that was fitted for this dataset, the effects of each study drug was compared to the effects of pooled vehicle. Overall food consumption was significantly different among the four treatment groups $(p=0.008)$, with animals on sibutramine consuming the least food during the experiment (Fig. 2). On average, food consumption was lower during the treatment phase of the experiment $(p<0.0001)$, and changed over time $(p=0.001)$. Nonetheless, as illustrated in Table 4 and Fig. 2, there was a significant three-way interaction between Treatment, Time and Phase of the treatment $(p=0.02)$.

In order to determine whether food consumption was significantly lower in animals treated with each of study drugs as compared to animals treated with vehicle during the treatment phase we conducted one-way ANOVA comparing areas under the curve for food consumption (Fig. 2, days 11-18). This analysis showed a significant effect of the drug: $F_{3,45}=4.12, p<0.05$, with rats treated with sibutramine or memantine consuming significantly less food than rats treated with vehicle ( $p=0.019 ; p=0.024$, respectively, Tukey's HSD test). As seen on the Fig. 2, effect of sibutramine changed over time and was most evident at the beginning of treatment while the effect of memantine was evident throughout treatment phase.

\section{Changes in body weight (Experiments 1-4)}

As shown of Fig. 3, all the groups have shown a gradual gain of the body weight over the time of experiments. Twoway repeated measures ANOVAs with treatment as between-subjects factor, week as repeated factor and interaction revealed the following values: $F_{1,96}=1.549$, $\mathrm{NS} ; F_{6,96}=314.9, p<0.001 ; F_{6,96}=2.996, p<0.01$ for sibutramine experiment; $F_{1,108}=0.01, \quad \mathrm{NS} ; \quad F_{6,108}=$ $392.2, \quad p<0.001 ; \quad F_{6,108}=0.25$, NS for memantine experiment, and $F_{1,84}=1.0, \mathrm{NS} ; F_{6,84}=165, p<0.001$ and $F_{6,84}=1.0$, NS for MTEP experiment, respectively. Despite significant interaction in sibutramine experiment, there was no significant difference between groups at any time-point as revealed by the post hoc Bonferroni's test.

Animals used in Experiment 4 were never offered the lard, and 2-way repeated measures ANOVA with treatment as between-subjects factor, week as repeated factor and interaction revealed the significant effect of week $\left(F_{3,135}=458.9, p<0.001\right)$ but no effect of treatment $\left(F_{3,135}=0.22, \mathrm{NS}\right)$ or interaction $\left(F_{9,135}=1.09, \mathrm{NS}\right)$. 

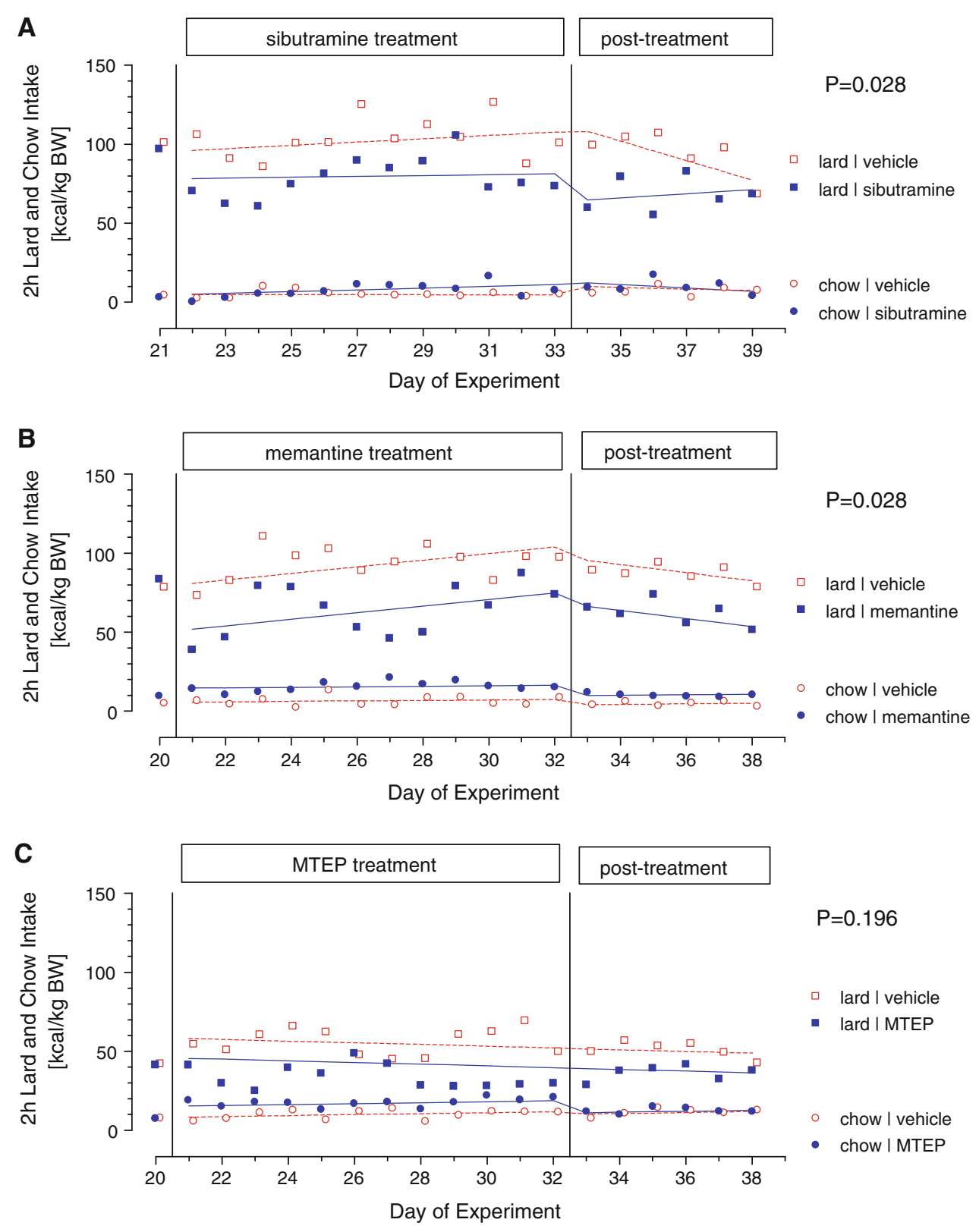

Fig. 1 2-h consumption of lard and chow at baseline, during repeated treatment with sibutramine (a), memantine (b) or MTEP (c), and during post-treatment phase. The group means, the GEE-fitted lines,

\section{Discussion}

Providing rats with an opportunity to consume a highly palatable food (lard) and a standard chow diet yielded a rapid and robust, "binge-like" level of lard consumption. Animals acquired significantly more energy from lard, which was available only for $2 \mathrm{~h}$ daily, than from chow, which was available at all times. Animals consumed large amounts lard despite their sated condition. This paradigm models a clinical phenomenon of an excessive, binge-type food consumption, where individuals repeatedly seek out and consume large amounts of highly palatable food, in a brief and the $p$ value for between-group differences (medication vs. vehicle control) are shown. Number of animals in each group $N=9$ a, $N=10 \mathbf{b}, N=8 \mathbf{c}$

and discrete period of time (Weltzin et al. 1991). The validity of this model to detect clinically effective medications was confirmed using sibutramine. The effects of chronic treatment with sibutramine to decrease energy intake in the proposed model are consistent with its effects to decrease food intake and binge-eating in the clinical setting (Arterburn et al. 2004; James et al. 2000; Wilfley et al. 2008) and in the human laboratory (Mitchell et al. 2003). The model of binge-eating of highly palatable food used here does not fully reflect other clinical features of human bingeeating such as binge-eating despite negative consequences or an increase of binge-eating in response to stress. 
Table 2 Memantine experiment GEE score statistics with food consumption as outcome variable for separate Lard and Chow models

\begin{tabular}{|c|c|c|c|}
\hline Source & BSE & $\chi_{(1)}^{2}$ & $p$ Value \\
\hline \multicolumn{4}{|l|}{ LARD } \\
\hline Intercept & $150.7(67.0)$ & & \\
\hline Drug $^{a}$ & 28.9 (11.6) & 4.80 & 0.0284 \\
\hline Time & $-2.56(1.78)$ & 0.07 & 0.7984 \\
\hline Phase $^{\mathrm{b}}$ & $-142.7(66.0)$ & 3.78 & 0.0519 \\
\hline Time $\times$ phase & $4.64(1.88)$ & 4.67 & 0.0307 \\
\hline \multicolumn{4}{|l|}{ CHOW } \\
\hline Intercept & $5.16(6.20)$ & & \\
\hline Drug $^{\mathrm{a}}$ & $-5.75(2.00)$ & 9.00 & 0.0027 \\
\hline Phase $^{\mathrm{b}}$ & $6.53(2.10)$ & 5.70 & 0.0170 \\
\hline Drug $\times$ phase & $-3.24(1.47)$ & 3.85 & 0.0498 \\
\hline Time & $0.15(0.18)$ & 0.64 & 0.4245 \\
\hline
\end{tabular}

Effects in table are drug (memantine or vehicle), phase (Treatment or Post-Treatment), and time-receiving treatment is in units of days (21-

32) for consumption outcome ( $\mathrm{kcal} / \mathrm{kg} \mathrm{b.w.).} \mathrm{Bold} p$ values denote significant effects

${ }^{a}$ Memantine was used as the reference

${ }^{\mathrm{b}}$ Post-treatment phase was used as the reference

Table 3 MTEP experiment GEE score statistics with food consumption as outcome variable for separate Lard and Chow models

\begin{tabular}{lrll}
\hline Source & \multicolumn{1}{l}{ BSE } & $\chi_{(1)}^{2}$ & $p$ Value \\
\hline LARD & & & \\
Intercept & $2.74(5.31)$ & & \\
Drug $^{\mathrm{a}}$ & $-0.62(1.52)$ & 1.67 & 0.1959 \\
Phase $^{\mathrm{b}}$ & $7.27(1.84)$ & 0.00 & 0.9738 \\
Time & $0.28(0.15)$ & 1.72 & 0.1903 \\
CHOW & & & \\
Intercept & $1.35(6.22)$ & & \\
Time & $0.31(0.17)$ & 2.74 & 0.0980 \\
Drug $^{\mathrm{a}}$ & $-0.91(2.18)$ & 3.17 & 0.0750 \\
Phase $^{\mathrm{b}}$ & $\mathbf{7 . 8 4}(\mathbf{1 . 8 2})$ & $\mathbf{6 . 4 1}$ & $\mathbf{0 . 0 1 1 4}$ \\
Drug $^{\times}$phase & $\mathbf{- 6 . 1 0 ( \mathbf { 1 . 4 4 } )}$ & $\mathbf{8 . 4 3}$ & $\mathbf{0 . 0 0 3 7}$ \\
\hline
\end{tabular}

Effects in table are drug (MTEP or vehicle), phase (Treatment or Post-Treatment), and time-receiving treatment is in units of days (2132) for consumption outcome ( $\mathrm{kcal} / \mathrm{kg}$ b.w.). Bold $p$ values denote significant effects

${ }^{a}$ MTEP was used as the reference

${ }^{\mathrm{b}}$ Post-treatment phase was used as the reference

However, this model can be used to study effects of medications on the consumption of highly palatable fatty foods.

Chronic treatment with sibutramine produced an overall decrease in energy intake, primarily due to decreased lard consumption. Interestingly, at the same time as animals decreased consumption of lard, they increased consumption of chow. This suggests a selective reduction of highly palatable food consumption with a compensatory increase of chow consumption rather than a global suppression of eating. After sibutramine treatment was stopped, the effect of treatment disappeared, as both groups consumed the baseline amount of energy from lard and chow by the end of the Post-Treatment Phase. This confirms that the observed effect was pharmacologically specific but relatively short-lasting. Memantine produced an effect on lard consumption that was similar to that of sibutramine, but unlike with sibutramine, the medication effect persisted throughout the Post Treatment Phase. Similarly to sibutramine, a compensatory increase in chow consumption under memantine occurred only during the Treatment Phase. MTEP produced a small decrease in lard consumption, and a compensatory increase in chow consumption during the medication Treatment phase, but these changes were not statistically different from that of the vehicle-treated group. Overall the effects of MTEP on lard and chow consumption were in the predicted direction, and similar to effects of sibutramine and memantine. In a control experiment, effects of study drugs were assessed in animals that were offered only the chow, though with an unlimited access. Under these conditions, repeated treatment with sibutramine produced initially a significant decrease in chow consumption, but this effect disappeared quickly. Treatment with memantine also produced decrease of chow consumption but only during the treatment phase, while treatment with MTEP had no effect on unlimited chow consumption.

When animals were given a choice to consume chow or lard, but access to lard was limited to only $2 \mathrm{~h}$ per day, they consumed a large amount of lard. Results observed here are consistent with other studies showing that limited access to highly palatable food produces a "binge-type" pattern of consumption in rats (Corwin et al. 1998; Wojnicki et al. 2008b; Wong et al. 2009) and baboons (Bisaga et al. 2008). The memantine-induced decrease in binge-type consumption of highly palatable food confirms earlier positive findings of memantine's effects in animal models of bingeeating disorder (Bisaga et al. 2008; Foltin et al. 2008). In laboratory animals, the pattern of binge-consumption of highly palatable foods is comparable to the binge pattern of drug and alcohol consumption (Colantuoni et al. 2001; Corwin et al. 1998). Considering that both NMDA receptors (Bisaga and Popik 2000; Herman et al. 2003) as well as mGlu5 receptors (Chiamulera et al. 2001) are involved in various manifestations of drug dependence and addiction, we hypothesize that binge-eating and binge pattern of drug and alcohol consumption may have shared regulatory mechanisms. Therefore, treatments developed for drug and alcohol addictions might be effective for the treatment of binge-eating. In the present study, treatment with MTEP did not produce clear effects on food intake, unlike what was previously shown in a baboon model (Bisaga et al. 2008). The fact that the effects of MTEP were in a similar 


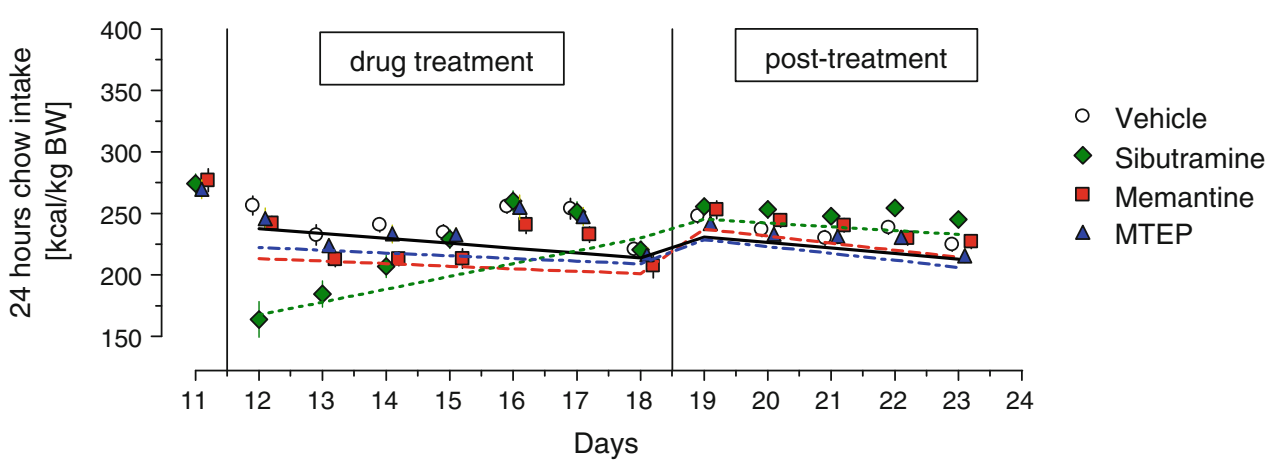

Fig. 2 24-h consumption of unlimited access chow at baseline, during repeated treatment with sibutramine, memantine, or MTEP and during post-treatment phase. Figure shows the group

Table 4 Experiment 4 GEE score statistics with food consumption ( $\mathrm{kcal} / \mathrm{kg}$ b.w.) as outcome variable in four groups of animals with unlimited access to chow

\begin{tabular}{|c|c|c|c|c|}
\hline Source & BSE & $\chi^{2}$ & $d f$ & $p$ Value \\
\hline Intercept & $316.2(23.0)$ & & & \\
\hline \multicolumn{5}{|l|}{ Drug $^{\mathrm{a}}$} \\
\hline Memantine & $29.9(40.7)$ & 11.7 & 3 & 0.008 \\
\hline Mtep & $19.3(41.6)$ & & & \\
\hline Sibu & $-13.1(27.3)$ & & & \\
\hline Phase $^{\mathrm{b}}$ & $-31.7(28.7)$ & 23.9 & 1 & $<0.0001$ \\
\hline Time & $-4.48(1.04)$ & 10.4 & 1 & 0.001 \\
\hline \multicolumn{5}{|l|}{ Drug $\times$ phase } \\
\hline Memantine & $-76.5(49.8)$ & 10.5 & 3 & 0.015 \\
\hline Mtep & $-54.9(36.4)$ & & & \\
\hline Sibu & $-229.1(53.5)$ & & & \\
\hline \multicolumn{5}{|l|}{ Drug $\times$ time } \\
\hline Memantine & $-1.24(1.82)$ & 12.0 & 3 & 0.008 \\
\hline Mtep & $-1.14(1.90)$ & & & \\
\hline Sibu & $1.44(1.22)$ & & & \\
\hline Time $\times$ period & $0.57(1.61)$ & 18.2 & 1 & $<0.0001$ \\
\hline \multicolumn{5}{|c|}{ Drug $\times$ phase $\times$ time } \\
\hline Memantine & $3.10(2.71)$ & 10.0 & 3 & 0.018 \\
\hline Mtep & $2.83(1.88)$ & & & \\
\hline Sibu & $12.9(3.05)$ & & & \\
\hline
\end{tabular}

Effects in table are drug (sibutramine, memantine, MTEP or vehicle), phase (Treatment or Post-Treatment), and time (days)

${ }^{a}$ Vehicle was used as the reference

b Post-treatment phase was used as the reference

direction to the effects of memantine albeit much weaker, may suggest that the dose of MTEP used was inadequate. In the present experiments, we used a $7.5 \mathrm{mg} / \mathrm{kg}$ dose of MTEP as compared to a $5 \mathrm{mg} / \mathrm{kg}$ dose of memantine. In baboons, doses of MTEP that produce comparable decreases in candy consumption were approximately twice as large as respective doses of memantine. On the other hand, a recent study demonstrated that MTEP and means \pm SEM and the GEE-fitted lines: solid, dotted, dash-dotted and dashed for vehicle, sibutramine, memantine and MTEP, respectively. Number of animals in each group was 12-13

memantine produce effects on the behavior of rats in the social interaction test in a similar range of doses (Koros et al. 2007). Alternatively, it cannot be excluded that the experiment conducted at a different season of the year resulted in an overall decrease of food intake resulting in an insignificant effect of the medication. This is certainly the limitation of the design used in the present study.

In the present study, the effects of memantine, an uncompetitive NMDA receptor antagonist, were comparable to the effects of sibutramine, a serotonin and noradrenaline reuptake inhibitor. This similarity in findings confirms that glutamatergic mechanisms may be as important as serotonergic mechanisms in regulating food consumption (Rammes et al. 2008). More interestingly, while the inhibitory effects of sibutramine on lard-bingeing were restricted to the treatment phase, a memantineinduced decrease appeared to persist even after the treatment was discontinued. Memantine is known to block the expression of neuroadaptations associated with the rewarding effects of potent reinforcers (Bisaga and Popik 2000) and was shown to inhibit relapse to opiate seeking even long after treatment discontinuation (Popik et al. 2006). We hypothesize that memantine prevented rebound relapse to binge-type fat consumption via a similar neuroadaptive mechanism.

We showed that under the condition of concurrent access to standard as well as highly preferred food both sibutramine and memantine selectively decreased consumption of lard but not chow. However, when only standard food was available, both sibutramine and memantine reduced food consumption, though animals rapidly developed tolerance to the consumption-suppressing effects of sibutramine. This suggests that in a situation of choice, these agents selectively alter the reinforcing effects of food with a higher palatability and reinforcing efficacy. This is consistent with the selective effects of memantine to reduce consumption of highly palatable food observed in the baboon model of binge-eating (Foltin et al. 2008). Therefore, in the situation of concurrent 
Experiment 1: sibutramine
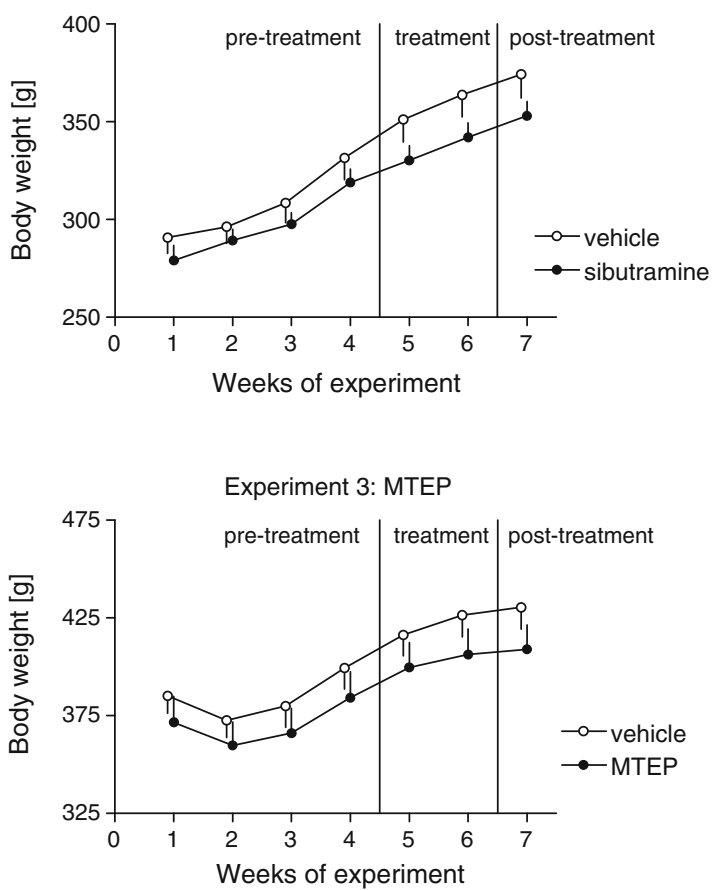

Fig. 3 Body weight of all the groups tested. Panels show group means \pm SEM. Panels 1-3 represents rats that were offered a limited access to the lard since the beginning of the experiment and were

access to different types of food memantine appears to be selective in reducing the reinforcing effects of food that is likely to be consumed for its hedonic rather than its homeostatic properties (Saper et al. 2002). This effect is comparable to the effect of memantine in selectively decreasing the effects of strongly rewarding stimuli, such as sexual interaction and morphine, but not of regular food (Popik et al. 2003). However, memantine can also produce decrease in the standard food consumption, presumably by enhancing satiation as seen previously (Bisaga et al. 2008; Foltin et al. 2008).

The "ideal" anti-binge medications should reduce nonhomeostatic food intake while leaving normal food intake unaffected; and the normalizing effect of medication on eating behavior should persist beyond the period of drug treatment (Yanovski 2003). Results of the present study, as well as previous studies using animal models (Bisaga et al. 2008; Foltin et al. 2008), suggest that memantine may have a uniquely attractive profile of clinical effectiveness. Initial uncontrolled clinical observations confirm the safety and potential effectiveness of memantine in reducing bingeeating with less effect on weight (Brennan et al. 2008; Hermanussen and Tresguerres 2005). Moreover, weight loss was not seen in memantine-treated patients with dementia (McShane et al. 2006) suggesting that memantine may possess a favorable clinical profile of effectiveness in reducing abnormal eating.
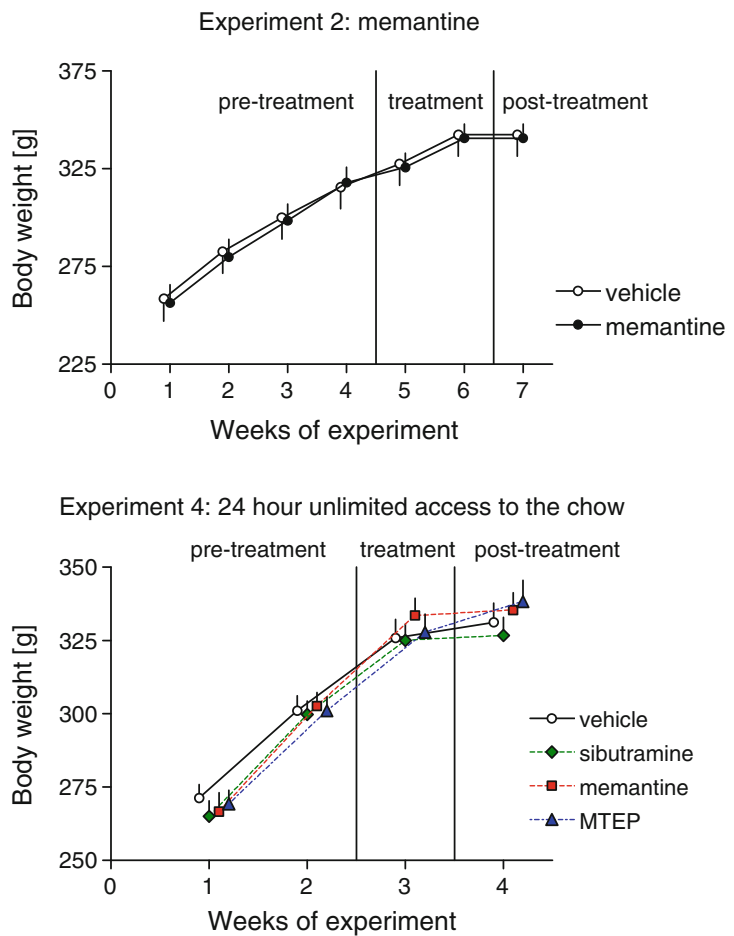

treated with respective medications during the treatment phase. Panel 4 represents rats that had continuous access to chow but no access to lard

In summary, the present study provides evidence that chronically administered memantine, an NMDA receptor glutamatergic antagonist, can selectively decrease consumption of highly palatable food with less effect on the consumption of a standard diet, and that this effect persists after the medication is discontinued. These findings suggest that memantine and NMDA receptor neurotransmission may be an attractive target for developing effective pharmacotherapies for binge-eating disorder and obesity.

Acknowledgments The assistance of Dr. Wojciech Danysz in obtaining funding for this study, Ms. Wendy Cheng for providing statistical consultation, and the assistance of Mr. Sean Ortman in editing the manuscript is gratefully acknowledged. Writing of this study was supported by the Funds for Statutory Activity of the Institute of Pharmacology Polish Academy of Sciences.

Open Access This article is distributed under the terms of the Creative Commons Attribution Noncommercial License which permits any noncommercial use, distribution, and reproduction in any medium, provided the original author(s) and source are credited.

\section{References}

Arterburn DE, Crane PK, Veenstra DL (2004) The efficacy and safety of sibutramine for weight loss: a systematic review. Arch Intern Med 164:994-1003

Avena NM, Rada P, Hoebel BG (2009) Sugar and fat bingeing have notable differences in addictive-like behavior. J Nutr 139:623-628 
Berthoud HR (2004) Neural control of appetite: cross-talk between homeostatic and non-homeostatic systems. Appetite 43:315-317

Bisaga A, Popik P (2000) In search of a new pharmacological treatment of drug addiction: $N$-methyl-D-aspartate (NMDA) antagonists. Drug Alcohol Depend 59:1-15

Bisaga A, Danysz W, Foltin RW (2008) Antagonism of glutamatergic NMDA and mGluR5 receptors decreases consumption of food in baboon model of binge-eating disorder. Eur Neuropsychopharmacol 18:794-802

Blundell JE, Finlayson G (2004) Is susceptibility to weight gain characterized by homeostatic or hedonic risk factors for overconsumption? Physiol Behav 82:21-25

Boggiano MM, Dorsey JR, Thomas JM, Murdaugh DL (2009) The Pavlovian power of palatable food: lessons for weight-loss adherence from a new rodent model of cue-induced overeating. Int J Obes (Lond) 33:693-701

Bradbury MJ, Campbell U, Giracello D, Chapman D, King CD, Tehrani L, Cosford ND, Anderson J, Varney MA, Strack AM (2005) Metabotropic glutamate receptor, mGlu5, is a mediator of appetite and energy balance in rats and mice. J Pharmacol Exp Ther 313:395-402

Brennan BP, Roberts JL, Fogarty KV, Reynolds KA, Jonas JM, Hudson JI (2008) Memantine in the treatment of binge eating disorder: an open-label, prospective trial. Int J Eat Disord 41:520-526

Buda-Levin A, Wojnicki FH, Corwin RL (2005) Baclofen reduces fat intake under binge-type conditions. Physiol Behav 86:176-184

Chiamulera C, Epping-Jordan MP, Zocchi A, Marcon C, Cottiny C, Tacconi S, Corsi M, Orzi F, Conquet F (2001) Reinforcing and locomotor stimulant effects of cocaine are absent in mGluR5 null mutant mice. Nat Neurosci 4:873-874

Cifani C, Polidori C, Melotto S, Ciccocioppo R, Massi M (2009) A preclinical model of binge eating elicited by yo-yo dieting and stressful exposure to food: effect of sibutramine, fluoxetine, topiramate, and midazolam. Psychopharmacology (Berl) 204:113-125

Colantuoni C, Schwenker J, McCarthy J, Rada P, Ladenheim B, Cadet JL, Schwartz GJ, Moran TH, Hoebel BG (2001) Excessive sugar intake alters binding to dopamine and mu-opioid receptors in the brain. NeuroReport 12:3549-3552

Corwin RL, Buda-Levin A (2004) Behavioral models of binge-type eating. Physiol Behav 82:123-130

Corwin RL, Wojnicki FH, Fisher JO, Dimitriou SG, Rice HB, Young MA (1998) Limited access to a dietary fat option affects ingestive behavior but not body composition in male rats. Physiol Behav 65:545-553

Devlin MJ, Yanovski SZ, Wilson GT (2000) Obesity: what mental health professionals need to know. Am J Psychiatry 157:854-866

Devlin MJ, Goldfein JA, Dobrow I (2003) What is this thing called BED? Current status of binge eating disorder nosology. Int J Eat Disord 34(Suppl):S2-S18

Erlanson-Albertsson C (2005) How palatable food disrupts appetite regulation. Basic Clin Pharmacol Toxicol 97:61-73

Fairburn CG, Cooper Z, Doll HA, Norman P, O'Connor M (2000) The natural course of bulimia nervosa and binge eating disorder in young women. Arch Gen Psychiatry 57:659-665

Foltin RW, Danysz W, Bisaga A (2008) A novel procedure for assessing the effects of drugs on satiation in baboons: effects of memantine and dexfenfluramine. Psychopharmacology (Berl) 199:583-592

Gass JT, Olive MF (2008) Glutamatergic substrates of drug addiction and alcoholism. Biochem Pharmacol 75:218-265

Hagan MM, Chandler PC, Wauford PK, Rybak RJ, Oswald KD (2003) The role of palatable food and hunger as trigger factors in an animal model of stress induced binge eating. Int J Eat Disord 34:183-197

Herman BH, Frankenheim J, Litten RZ, Sheridan PH, Weight FF, Zukin SR (2003) Glutamate and addiction. Humana Press, Totowa
Hermanussen M, Tresguerres JA (2005) A new anti-obesity drug treatment: first clinical evidence that, antagonising glutamategated $\mathrm{Ca} 2+$ ion channels with memantine normalises bingeeating disorders. Econ Hum Biol 3:329-337

Jackson HC, Needham AM, Hutchins LJ, Mazurkiewicz SE, Heal DJ (1997) Comparison of the effects of sibutramine and other monoamine reuptake inhibitors on food intake in the rat. Br J Pharmacol 121:1758-1762

James WP, Astrup A, Finer N, Hilsted J, Kopelman P, Rossner S, Saris WH, Van Gaal LF (2000) Effect of sibutramine on weight maintenance after weight loss: a randomised trial. STORM Study Group. Sibutramine Trial of Obesity Reduction and Maintenance. Lancet 356:2119-2125

Koros E, Rosenbrock H, Birk G, Weiss C, Sams-Dodd F (2007) The selective mGlu5 receptor antagonist MTEP, similar to NMDA receptor antagonists, induces social isolation in rats. Neuropsychopharmacology 32:562-576

Lee JH, Herzog TA, Meade CD, Webb MS, Brandon TH (2007) The use of GEE for analyzing longitudinal binomial data: a primer using data from a tobacco intervention. Addict Behav 32:187-193

McShane R, Areosa Sastre A, Minakaran N (2006) Memantine for dementia. Cochrane Database Syst Rev CD003154

Mitchell JE, Gosnell BA, Roerig JL, de Zwaan M, Wonderlich SA, Crosby RD, Burgard MA, Wambach BN (2003) Effects of sibutramine on binge eating, hunger, and fullness in a laboratory human feeding paradigm. Obes Res 11:599-602

Popik P, Wrobel M, Rygula R, Bisaga A, Bespalov AY (2003) Effects of memantine, an NMDA receptor antagonist on place preference conditioned with drug and non-drug reinforcers in mice. Behav Pharmacol 14:237-244

Popik P, Wrobel M, Bisaga A (2006) Reinstatement of morphine conditioned reward is blocked by memantine. Neuropsychopharmacology 31:160-170

Rammes G, Danysz W, Parsons CG (2008) Pharmacodynamics of memantine: an update. Curr Neuropharmacol 6:55-78

Saper CB, Chou TC, Elmquist JK (2002) The need to feed: homeostatic and hedonic control of eating. Neuron 36:199-211

Tanofsky-Kraff M, Cohen ML, Yanovski SZ, Cox C, Theim KR, Keil M, Reynolds JC, Yanovski JA (2006) A prospective study of psychological predictors of body fat gain among children at high risk for adult obesity. Pediatrics 117:1203-1209

Vartanian LR, Schwartz MB, Brownell KD (2007) Effects of soft drink consumption on nutrition and health: a systematic review and meta-analysis. Am J Public Health 97:667-675

Walsh BT, Devlin MJ (1998) Eating disorders: progress and problems. Science 280:1387-1390

Weltzin TE, Hsu LK, Pollice C, Kaye WH (1991) Feeding patterns in bulimia nervosa. Biol Psychiatry 30:1093-1110

Wilfley DE, Crow SJ, Hudson JI, Mitchell JE, Berkowitz RI, Blakesley V, Walsh BT (2008) Efficacy of sibutramine for the treatment of binge eating disorder: a randomized multicenter placebo-controlled double-blind study. Am J Psychiatry 165:51-58

Wojnicki FH, Charny G, Corwin RL (2008a) Binge-type behavior in rats consuming trans-fat-free shortening. Physiol Behav 94:627-629

Wojnicki FH, Johnson DS, Corwin RL (2008b) Access conditions affect binge-type shortening consumption in rats. Physiol Behav 95:649-657

Wong KJ, Wojnicki FH, Corwin RL (2009) Baclofen, raclopride, and naltrexone differentially affect intake of fat/sucrose mixtures under limited access conditions. Pharmacol Biochem Behav 92:528-536

Yanovski SZ (2003) Binge eating disorder and obesity in 2003: could treating an eating disorder have a positive effect on the obesity epidemic? Int J Eat Disord 34(Suppl):S117-S120

Zeger SL, Liang KY (1986) Longitudinal data analysis for discrete and continuous outcomes. Biometrics 42:121-130 